\title{
Faktor-Faktor yang Berhubungan Dengan Kunjungan Ibu Dengan Balita ke Posyandu
}

\author{
Alfrida Fitriyah ${ }^{1}$, Niken Purbowati ${ }^{2}$, Willa follona ${ }^{3}$ \\ 1,2,3 Poltekkes Kemenkes Jakarta III. Pondok Melati, Kota Bekasi Jawa Barat 17415 Indonesia
}

\begin{tabular}{l}
\hline ARTICLE INFORMATION \\
\hline Article Trace \\
Submission: August 15, 2019 \\
Final Revision: September 26, 2019 \\
Available online: October 26, 2019 \\
\hline
\end{tabular}

Kata kunci :

Balita, kunjungan posyandu

Key Word :

Children under 5 years old, posyandu

Contact:

alfridafitriyah@gmail.com

\begin{abstract}
A B S T R A K
Posyandu berguna untuk memberdayakan masyarakat dan memberikan kemudahan memperoleh pelayanan kesehatan dasar. Tujuan penelitian ini adalah untuk mengetahui faktor yang berhubungan dengan kunjungan balita ke Posyandu di wilayah kerja Puskesmas Kelurahan Pegangsaan Dua B Kecamatan Kelapa Gading, Jakarta Utara Tahun 2018. Penelitian ini merupakan penelitian deskriptif analitik dengan desain cross sectional. Dengan sampel 75 ibu balita yang dipili secara acak di 6 Posyandu. Hasil penelitian didapatkan ibu balita yang berperilaku baik berkunjung ke Posyandu masih rendah dari target sebanyak $68 \%$. Ada 4 variabel secara statistik berhubungan dengan perilaku kunjungan ke Posyandu yaitu lebih banyak pada ibu yang berpengetahuan baik tentang Posyandu, berjarak dekat, serta berpendapat peran kader dan nakes yang baik. Analisis multivariat dengan metode regresi logistik prediksi menghasilkan variabel dominan yaitu jarak, dan yang menjadi confounding yaitu peran kader. Disarankan untuk melakukan dan meningkatkan monitoring upaya promosi kesehatan dengan supervisi langsung ke Posyandu dan memberikan penyuluhan kepada masyarakat tentang kegiatan yang ada di Posyandu.
\end{abstract}

\begin{abstract}
A B S T R A C T
Posyandu is useful to empower communities and to provide the easiest of obtaining basic health services. The objectives of this study was conducted to determine the related factors with the toodlers visits to Posyandu in the Working Area of Health Center Pegangsaan Dua B, Kelapa Gading, North Jakarta in 2018. This study was an analitic descriptive with cross sectional design. There were 75 samples of toddlers mothers randomly chosen in 6 Posyandu. The results obtained are well behaved toddler mother as much as $68 \%$. There are four variables that were statistically related with the behavior visits to Posyandu namely: there were more on good knowledge, short distance, and positive thinking to cadres and health workers. Multivariate analysis with prediction logistic regression method produces dominant variable that is distance, and become confounding is role of cadre. It is further recommended to perform and improve the monitoring of health promotion efforts with direct supervision to Posyandu and provide conseling to the public about the existing activities in Posyandu.
\end{abstract}




\section{PENDAHULUAN}

Pemberdayaan masyarakat di bidang kesehatan adalah proses pemberian informasi kepada individu, keluarga atau kelompok (klien) secara terus menerus dan berkesinambungan mengikuti perkembangan klien, serta proses membantu klien, agar klien tersebut berubah dari tidak tahu menjadi tahu atau sadar (aspek pengetahaun atau knowledge) dari tahu menjadi mau (aspek sikap atau attitude), dan dari mau menjadi mampu melaksanakan perilaku yang diperkenalkan.

Keberadaan Posyandu sangat diperlukan dalam mendekatkan upaya promotif dan preventif kepada masyarakat, terutama terkait peningkatan status gizi masyarakat, serta upaya kesehatan ibu dan anak. Pos Pelayanan Terpadu (Posyandu) merupakan salah satu bentuk UKBM yang paling memasyarakat karena dikelola dan diselenggarakan dari, oleh, untuk dan bersama masyarakat. Posyandu berfungsi memberdayakan dan memberikan kemudahan kepada masyarakat dalam memperoleh pelayanan kesehatan dasar bagi masyarakat terutama ibu, bayi dan anak balita. Posyandu memiliki kegiatan program prioritas seperti kesehatan ibu dan anak, perbaikan gizi, imunisasi, pencegahan penanganan diare, dan KB. Harapannya masyarakat yang rutin hadir ke Posyandu dapat mempunyai bayi balita yang sehat sehingga menjadi aset yang berkualitas (kemenkes, 2015). Tingkatan posyandu diukur dengan beberapa indikator seperti jumlah buka posyandu per tahun, jumlah kader yang bertugas, jumlah cakupan 5 kegiatan, penyelenggaraan program tambahan, dan dana sehat yang dikelola oleh masyarakat.

Terdapat beberapa kendala yang dihadapi terkait dengan kunjungan ke posyandu. Permasalahan tersebut antara lain berupa dana operasional dan sarana prasarana untuk menggerakkan kegiatan Posyandu, tingkat pengetahuan kader dan kemampuan petugas dalam pemantauan pertumbuhan dan konseling, tingkat pemahaman keluarga dan masyarakat terhadap manfaat Posyandu, serta pelaksanaan pembinaan kader (Kemenkes, RI, 2012).

Hasil penelitian sebelumnya mengatakan bahwa faktor-faktor yang mempengaruhi partisipasi ibu ke posyandu dapat berupa umur ibu, status maternal, suku, pendapatan rumah tangga, pekerjaan, pengetahuan, pendidikan, sikap ibu, kepercayaan ibu, kepuasan terhadap pelayanan Posyandu, kader yang berkualitas, dukungan pemangku kepentingan, jarak, dan tenaga kesehatan (Nazri, dkk, 2015 dan Maulana, A, 2013).

Studi pendahuluann terhadap sepuluh ibu yang memiliki balita di salah satu kelurahan di Jakarta didapatkan data bahwa tiga ibu berkunjung ke posyandu dengan alasan kunjungan datang keposyandu karena mendapat informasi dari kader, sedangkan tujuh ibu tidak berkunjung ke posyandu karena alasan lebih memilih datang ke fasilitas kesehatan yang lain. Penelitian ini bertujuan mengetahui faktor-faktor yang mempengaruhi ibu membawa balitanya ke posyandu.

\section{METODE PENELITIAN}

Jenis penelitian yang digunakan dalam penelitian ini adalah deskriptif analitik dengan desain cross sectional. populasi dari penelitian ini adalah seluruh ibu yang memiliki balita di wilayah kerja salah satu puskesmas kelurahan di Jakarta Utara. Dalam penelitian ini metode pengambilan sampel menggunakan Proportional Sampling dan dengan cara teknik Accidental Sampling. Jumlah sampel penelitian adalah 75 responden. Sumber data yang digunakan pada penelitian ini adalah data primer yang didapatkan melalui wawancara langsung dengan menggunakan kuesioner terstruktur yang ditanyakan kepada responden. Analisis data menggunakan uji statistic Chi-Square dengan alpha 0,05 dan CI 95\%.

\section{HASIL DAN PEMBAHASAN}

Hasil penelitian pada tabel 1 menunjukkan adanya hubungan yang bermakna antara pengetahuan dan kunjungan ke Posyandu (Pvalue $=0,0001)$ dan $\mathrm{OR}=13,886$. Ibu yang memiliki pengetahuan baik serta aktif berkunjung ke Posyandu sebanyak $47 \mathrm{ibu}$ $(81,00 \%)$, sedangkan ibu yang memiliki pengetahuan baik namun tidak aktif berkunjung ke Posyandu sebanyak 11 ibu $(19,00 \%)$. Hasil penelitian ini sejalan dengan Teori Green tentang perilaku seseorang dipengaruhi oleh faktor predisposisi yaitu pengetahuan. 
The Southeast Asian Journal of Midwifery Vol. 5, No.2, Oktober, 2019, p: 79-83

Tabel 1. Hubungan karakteristik responden dengan kunjungan ke posyandu

\begin{tabular}{|c|c|c|c|c|c|c|}
\hline \multirow{3}{*}{ karakteristik responden } & \multicolumn{4}{|c|}{ kunjungan keposyandu } & \multirow{3}{*}{ p value } & \multirow{3}{*}{ or } \\
\hline & \multicolumn{2}{|c|}{ Tidak aktif } & \multicolumn{2}{|c|}{ Aktif } & & \\
\hline & $\mathbf{n}$ & $\%$ & $\mathbf{n}$ & $\%$ & & \\
\hline \multicolumn{7}{|l|}{ Pengetahuan } \\
\hline kurang (< mean) & 12 & 26.3 & 4 & 23.5 & 0.0001 & 13.886 \\
\hline baik $(\geq$ mean $)$ & 11 & 33.9 & 47 & 81.0 & & \\
\hline \multicolumn{7}{|l|}{ Jarak posyandu } \\
\hline$>500$ meter & 10 & 90.9 & 1 & 9.1 & 0.0001 & 35,714 \\
\hline$<500$ meter & 14 & 21.9 & 50 & 78.1 & & \\
\hline \multicolumn{7}{|l|}{ Peran kader } \\
\hline kurang $(<$ mean $)$ & 6 & 18.2 & 27 & 81.8 & 0.043 & 0,296 \\
\hline baik ( $\geq$ mean $)$ & 18 & 42.9 & 24 & 57.1 & & \\
\hline \multicolumn{7}{|l|}{ Peran Tenaga Kesehatan } \\
\hline kurang $(<$ mean) & 6 & 75 & 2 & 25.0 & 0.018 & 8.167 \\
\hline baik $(\geq$ mean $)$ & 18 & 26.9 & 49 & 73.1 & & \\
\hline
\end{tabular}

Hal tersebut berkaitan dengan analisis Hutami (2015) yang mengatakan bahwa pengetahuan mengubah perilaku ke arah yang diinginkan. Dari hasil penelitian ini, analisis peneliti adalah tingginya pengetahuan ibu menghasilkan tingginya kesadaran ibu akan pemanfaatan sarana kesehatan khususnya untuk memantau kesehatan balitanya, sehingga angka kunjungan balita ke posyandu akan semakin tinggi dan kunjungan menjadi rutin. Jika ibu mengetahui manfaat Posyandu dan pelayanan yang diberikan, maka ibu dapat menilai dan berbuat sesuatu untuk berusaha memperbaiki dan meningkatkan kesehatan anaknya

Hasil penelitian ini menunjukkan adanya hubungan yang bermakna antara jarak dengan kunjungan ke Posyandu (p-value $=0,0001)$ dan OR 35,714. Ibu yang memiliki jarak yang dekat ke Posyandu dan aktif berkunjung ke Posyandu sebanyak 50 ibu $(78,10 \%)$ sedangkan ibu yang berjarak dekat namun tidak aktif ke Posyandu sebanyak 14 ibu $(21,90 \%)$. Hal in berkaitan dengan Teori Green tentang faktor pendukung yaitu jarak yang dibutuhkan untuk mendukung perilaku kesehatan. Dari hasil penelitian ini, analisis peneliti adalah kemudahan untuk mengakses lokasi atau tempat kegiatan, dan waktu pelaksanaan kegiatan dapat menjadi faktor pendukung partisipasi yang dilakukan oleh seseorang. Semakin dekat jarak tempuh rumah dengan tempat penyelenggaraan Posyandu, maka akan lebih banyak masyarakat memanfaatkan Posyandu.

Hasil penelitian ini menunjukkan adanya hubungan yang bermakna antara peran kader dengan kunjungan ke Posyandu (P-value =
$0,043)$ dan $\mathrm{OR}=0,296$. Ibu yang beranggapan peran kader baik dan aktif berkunjung ke Posyandu sebanyak 24 ibu (57,10\%), sedangkan ibu yang beranggapan bahwa peran kader baik namun tidak aktif berkunjung ke Posyandu sebanyak $18 \mathrm{ibu}(42,90 \%)$. Hal ini berkaitan dengan Teori Green tentang factor pendorong berupa dukungan, bahwa dukungan dapat mempengaruhi tindakan seseorang untuk melakukan sesuatu.

Dari hasil penelitian ini, analisis peneliti adalah keterampilan kader merupakan salah satu kunci keberhasilan dalam sistem pelayanan di posyandu, karena dengan pelayanan kader yang terampil akan mendapat respon positif dari ibuibu yang memiliki balita, sehingga terkesan ramah dan baik serta pelayanannya teratur. Maka hal tersebut dapat mendorong para ibu balita rajin berkunjung ke posyandu.

Hasil penelitian ini menunjukkan adanya hubungan yang bermakna antara peran nakes dengan kunjungan ke Posyandu (Pvalue $=0,018$ ) dan $\mathrm{OR}=8,167$. Ibu yang beranggapan peran nakes baik dan aktif berkunjung ke Posyandu sebanyak 49 ibu $(73,10 \%)$, sedangkan ibu yang beranggapan bahwa peran nakes baik namun tidak aktif berkunjung ke Posyandu sebanyak 18 ibu $(26,90 \%)$. Hal ini sejalan dengan penelitian Pinasang (2015) yang mengatakan bahwa peran nakes yang bertugas di Posyandu apabila kurang simpatik dalam memberikan pelayanan kesehatan, maka dapat menghambat ibu untuk berkunjung ke Posyandu. Dari hasil penelitian ini, anaisis peneliti adalah peran tenaga kesehatan sebagai fasilitator Posyandu 
berkewajiban untuk menyampaikan inovasi dan atau mempengaruhi penerima manfaat, sehingga dengan kesadaran dan kemampuannya sendiri
Posyandu dapat mengadopsi inovasi yang disampaikan. Hal tersebut dapat mendorong para ibu untuk rajin berkunjung ke Posyandu.

Tabel 2: pemodelan awal

\begin{tabular}{ccccc}
\hline \multirow{2}{*}{ Variabel } & \multirow{2}{*}{ Sig } & \multirow{2}{*}{ Exp (B) } & \multicolumn{2}{c}{$95 \%$ C.I. for Exp (B) } \\
\cline { 4 - 5 } & & & Lower & Upper \\
\hline Pengetahuan & 0,003 & 12,164 & 2,353 & 62,879 \\
Jarak & 0,001 & 57,731 & 4,833 & 681,017 \\
Peran Kader & 0,148 & 0,303 & 0,060 & 1,527 \\
Peran Nakes & 0,063 & 7,067 & 0,898 & 55,630 \\
\hline
\end{tabular}

Tabel 3: Pemodelan akhir

\begin{tabular}{ccccc}
\hline \multirow{2}{*}{ Variabel } & \multirow{2}{*}{ Sig } & \multirow{2}{*}{ Exp (B) } & \multicolumn{2}{c}{$95 \%$ C.I. for Exp (B) } \\
\cline { 4 - 5 } & & & Lower & Upper \\
\hline Pengetahuan & 0,003 & 12,164 & 2,353 & 62,879 \\
Jarak & 0,001 & 57,731 & 4,833 & 681,017 \\
Peran Kader & 0,148 & 0,303 & 0,060 & 1,527 \\
Peran Nakes & 0,063 & 7,067 & 0,898 & 55,630 \\
\hline
\end{tabular}

Model akhir analisis multivariat menghasilkan variabel yang memiliki hubungan yang signifikan dengan kunjungan balita ke Posyandu yaitu variabel pengetahuan, jarak, peran kader, dan peran nakes. Hasil regresi logistik yang digunakan adalah nilai Pvalue dan OR adjusted, yaitu OR murni yang sudah dikontrol dengan variabel independen lain yang dapat dilihat pada tabel 3 .

Pada tabel 3 terlihat bahwa terdapat hubungan yang bermakna antara pengetahuan ( $\mathrm{p}=$ $0,003)$ dan jarak $(\mathrm{p}=0,001)$ dengan kunjungan ke Posyandu. Berdasarkan hasil analisis dalam penelitian ini, variabel yang paling dominan adalah jarak sedangkan variabel yang nilai Pvalue nya $>0,05$ adalah peran kader yang merupakan variabel confounding. Hasil analisis didapatkan Odds Ratio (OR) dari variabel jarak adalah 57,371 , artinya ibu yang memiliki balita 0 59 bulan akan berpeluang 57 kali lebih sering datang ke Posyandu apabila jarak ke Posyandu dekat dibandingkan dengan ibu yang memiliki jarak yang jauh.

\section{KESIMPULAN}

Kunjungan ibu yang memiliki balita ke posyandu dipengaruhi oleh factor didalam ibu seperti pengetahuan dan factor di luar ibu seperti jarak, peran kader dan peran tenaga kesehatan. Hasil penelitian ini menunjukkan untuk meningkatkan angka kunjungan posyandu, maka tidak cukup dengan meningkatkan pengetahuan ibu tentang pentingnya posyandu.

\section{DAFTAR PUSTAKA}

Hutami IR, Ardianto E, 2015. Faktor yang Berhubungan dengan Kunjungan Balita di Posyandu Desa Bulak Lor Wilayah Kerja Puskesmas Jatibarang Factors About Visit of Children Under Five at Posyandu. Jatibarang: Universitas Wiralodra

Indonesia Ministry of Health (Kemenkes RI). 2015. DKI Jakarta Health Profile. Jakarta: Kemenkes RI

Kalsum U. 2013. Child morbidity, level of parent' $s$ education, and accessibility to health facilities as factors affecting Posyandu utilization..Jambi: Health Scince Indonesia.

Maulana A. 2013. Hubungan Keaktifan Ibu Dalam Posyandu Dengan Penurunan Jumlah Balita Bawah Garis Merah (Bgm) Di Desa Suko Jember Kecamatan Jelbuk Kabupaten Jember. Jember: Universitas Jember.

Nazri C, dkk. 2015. Factors influencing mother's participation in Posyandu for improving nutritional status of children under-five in Aceh Utara district, Aceh 
province, Indonesia. Aceh: BMC Public Health.

Notoatmodjo. 2010. Metodologi Penelitian Kesehatan. Jakarta: Rineka Cipta.

Pinasang VN, Rantung M, Keintjem F. 2015. Faktor-Faktor Yang Berhubungan
Dengan Kurangnya Kunjungan Anak Balita Di Posyandu. Manado : JIB.

Sugiyarti R, Aprilia V, Suci Hati F. 2014. Kepatuhan Kunjungan Posyandu dan Status Gizi Balita di Posyandu Karangbendo Banguntapan, Bantul Yogyakarta. Yogyakarta: JNMI. 